\title{
Administrative Supplement
}

National Cancer Institute

\section{Source}

National Cancer Institute. Administrative Supplement. NCI Thesaurus. Code C20071.

Mechanism to fund current awardees whose research is going better than expected or who are poised to test new ideas. 